\title{
Determination of Energy Properties of Fuelwood from Five Selected Tree Species in Tropical Highlands of Southeast Ethiopia
}

\author{
Hailu Manaye Desta $\mathbb{D}^{1}$ and Cherinet Seboka Ambaye $\mathbb{D}^{2}$ \\ ${ }^{1}$ Department of Environmental Science, Madda Walabu University, Bale Zone, Robe, P.Box: 247, Ethiopia \\ ${ }^{2}$ Department of Physics, Madda Walabu University, Bale Zone, Robe, P.Box: 247, Ethiopia \\ Correspondence should be addressed to Cherinet Seboka Ambaye; janbo2012@gmail.com
}

Received 13 August 2019; Revised 30 October 2019; Accepted 3 February 2020; Published 1 March 2020

Academic Editor: Ching-Yuan Chang

Copyright ( 2020 Hailu Manaye Desta and Cherinet Seboka Ambaye. This is an open access article distributed under the Creative Commons Attribution License, which permits unrestricted use, distribution, and reproduction in any medium, provided the original work is properly cited.

\begin{abstract}
The aim of this study was to determine the energy properties of fuelwood samples which are preferred and used by local communities. The study used both cross-sectional survey of households and field survey. Systematic household sampling was used for household and random sampling for tree species. The chosen sample sizes for households in the study were 134 . The cross-sectional survey of the local community on orderly preference of fuelwood consumption listed Acacia nilotica, Acacia etbaica, Olea africana, Acacia seyal, and Acokanthera schimperi. However, for the laboratory result and detail principal component analysis (PCA) of tree species in their density and moisture, ash, volatile, and fixed carbon contents, Olea africana was strongly recommended for fuelwood preference followed by Acacia nilotica, Acacia etbaica, Acacia seyal, and Acokanthera schimperi. The identification of community preference and scientific assessment on fuelwood consumption on different tree species will enhance the expansion of their plantation program in the region.
\end{abstract}

\section{Introduction}

Energy constitutes one of the most important aspects of human life. It is a commodity that is vital for the existence of modern life [1]. Despite the various source of energy in developing countries, it is estimated that approximately 2.5 billion people rely on biomass fuels to meet their cooking, heating, and lighting needs. For many of these countries, more than 90 percent of total household fuel is biomass [2]. Traditionally, energy in the form of firewood, twigs, and charcoal has been the major source of renewable energy for many developing countries [3].

In Africa, solid biofuels are reported to account for about $50 \%$ of African's energy need [1]. Likewise, in Ethiopia, 92\% of the total energy consumption came from traditional fuel [4]. Without new policies, the number of people that rely on biomass fuels is expected to increase to 2.7 billion by 2030 (about one-third of the world's population) due to population growth [5].

Fuelwood is the most dominant source of energy in Ethiopia and is used significantly in both rural and urban com- munities for cooking and many other heating applications [6]. Thus, in many developing countries over the world, wood fuel will continue to be the main cooking energy in the rural households in the future [7]. Nowadays, wood energy consumption is no longer the primary cause of global deforestation but rather the clearing of land for farming. Around $95 \%$ of cleared forest areas in sub-Saharan Africa, for example, are attributed to new land requirements for crops [8]. However, concentrated industrial and urban demand for firewood combined with weak regulation and control can still contribute to forest degradation and deforestation around major centers of consumption [9]. As a response strategy for the impact, community-based forest management that aims at promoting stewardship and responsibility among local communities and user groups can create incentives for resource-savings and sustainable approaches to forestry with the introduction of innovative technical developments; firewood and charcoal can become a renewable and climate-friendly energy source for populations in rural and urban settings [10]. The environmental and health benefits of fuel are primarily dependent on its 
processing and usage techniques. Wood fuels in inefficient and traditional ways have severe implications for health, productivity, gender equality, and the environment [11]. To provide the country with environmental-friendly and sustainable energy source, fuelwood mainly high fixed carbon firewood can be taken as one alternative. In the world, there are different related articles such as wood-based biomass energy development [12] and firewood and charcoal properties [13, 14]. Similarly, in Africa, the article concerning fuelwood is "Evaluation of fuel properties of six tropical hardwood timber species for briquettes" [15]. Even though Ethiopia is profoundly depending on fuelwoods and biomasses as leading energy resources both in the towns and rural parts [16], there are little research reports on the characterization of energy properties scientifically in terms of determination of their density; inflammability; volatile matter, ash, moisture, and fixed carbon contents; and the like. As far as the knowledge of the researcher concerned, the energy properties of fuelwood in the midhighlands of Goro district are unavailable. In spite of the absence of scientific data, local people had been traditionally using specific tree species for firewood for generations of energy; there is lack of scientific data to validate their preferences of these species.

Experience in Goro district would show that such a heavy reliance on a limited resource base and inefficient mode of utilization of these traditional fuels was the characteristics of household energy consumption. Therefore, the problem is alarming and needs an urgent scientific study to identify tree species that have efficient energy to mitigate the problem in the district.

The general objective of this study is to determine the energy properties of fuelwood made from five selected tree species in midhighlands of Goro district. The information generated from this study can be useful particularly for rural and urban communities that use fuelwood as the source of energy. The research outcome helps them to choose firewood types on the bases of the fixed carbon content. Using high value of fixed carbon fuelwood reduces pressure on deforestation.

\section{The Study Area and Data Method}

Goro district is situated $490 \mathrm{~km}$ southeast of Addis Ababa and $60 \mathrm{~km}$ from the zonal capital Robe as observed in Figure 1. It is geographically located between $6^{\circ} 29^{\prime \prime}-7^{\circ} 15^{\prime \prime} \mathrm{N}$ latitude and $40^{\circ} 10^{\prime \prime}-40^{\circ} 45^{\prime \prime}$ longitude. It is the administrative center of Goro district. It covers a total area of $1339 \mathrm{~km}^{2}$ (133,900 ha), with elevation ranging from $1200 \mathrm{~m}$ to 2800 meters a.s.l. [17]. Goro district is the 14th largest among the zone district. The district is subdivided into twenty-six kebeles and three urban centers. The specific area of this research for the tree species is Gadulla kebele which is located $21 \mathrm{~km}$ northeast of Goro town. In Gadulla, there is a 400-hectare natural forest.

According to agricultural classification based on crops grown, the district has three agroclimatic zones which constitute highland $34.48 \%$, semihighland $31.93 \%$, and lowland $27.59 \%$ according to the Goro district agricultural and natural resource office report (2017). The mean annual rainfall of the district is about $750 \mathrm{~mm}-1150 \mathrm{~mm}$. There are two rainfall and cropping seasons: the main rainy season from March to May and the short rainy season from August to November. The former contributes $55 \%$ of the total annual crop production. The latter covers areas at the high and medium altitudes. The annual mean temperature lies between $25^{\circ} \mathrm{C}$ and $30^{\circ} \mathrm{C}$ in lowland areas and $16^{\circ} \mathrm{C}$ and $20^{\circ} \mathrm{C}$ in highland areas [17].

According to the agricultural and natural resource office document, the most common types of vegetation of the district includes Acacia brevispica, Acokanthera schimperi, Olea africana, Acacia bussei, Salix mucronata, Albizia gummifera, Apodytes dimidiata, Acacia albida, Ficus sycomorus, Acacia lahai, Acacia tortilis, Acacia seyal, and Acacia oerfota. Acacia wood species is the most dominant tree species in the study area.

The population entirely depends on firewood and charcoal. Solar power and biogas usage in the district is insignificant. The community is entirely relaying on firewood and charcoal for energy consumption. The awareness on the use of efficient fuel and modern stoves is also weak. Their economy is also affected by price rising of firewood and charcoal supply.

A systematic sampling design was used in this study to collect data on woody species. The study utilized both actual field measurements and laboratory analysis. The required materials for the field studies were an electronic balance for measuring weight of the samples, GPS for demarcating the study area, camera for photographing the study area, and sound recorder for recording focus group discussion. The samples were contained in the sample holder. A saw (axe) was used for chopping the samples and a meter tape for measurement of length and the circumferences of the samples. The data obtained were registered by pencil on a notebook, and a thermometer was used for recording the temperature of the study area. All the samples were weighed on a digital analytical balance (ADAM, Model AFP-110L, England) with $120 \mathrm{~g}$ loading capacity and \pm 0.0001 precision. A heating furnace of a UK manufacturer called CWF1313-230SN working in the temperature between $750^{\circ} \mathrm{C}$ and $1300^{\circ} \mathrm{C}$ was used for heating the sample. A drying oven (Digitheat, J.P. Selecta, Germany) was used for drying the samples placed on an evaporating dish. A beaker (Duran, Germany) was used for measuring different volumes of samples.

2.1. Sample Size. To collect the necessary data, a questionnaire was designed and employed using the following procedure. The number of the sample household selected for the questionnaire was determined using the following formula [18]:

$$
n=\frac{\text { no }}{(1+(\mathrm{no}-1) / N)} \longrightarrow \text { no }=\frac{z^{2} p q}{d^{2}}
$$

where no is the desired sample size when the population is greater than 10,$000 ; n$ is the number of sample size when the population is less than 10,000 ; $z$ is the $95 \%$ confidence limit, i.e., $1.96 ; p$ is 0.1 , i.e., proportion of the population to be included in the sample, i.e., $10 \% ; q=1-0.1$, i.e., $0.9 ; N$ is the total number of population; and $d$ is the margin of error or degree of accuracy desired (0.05). 


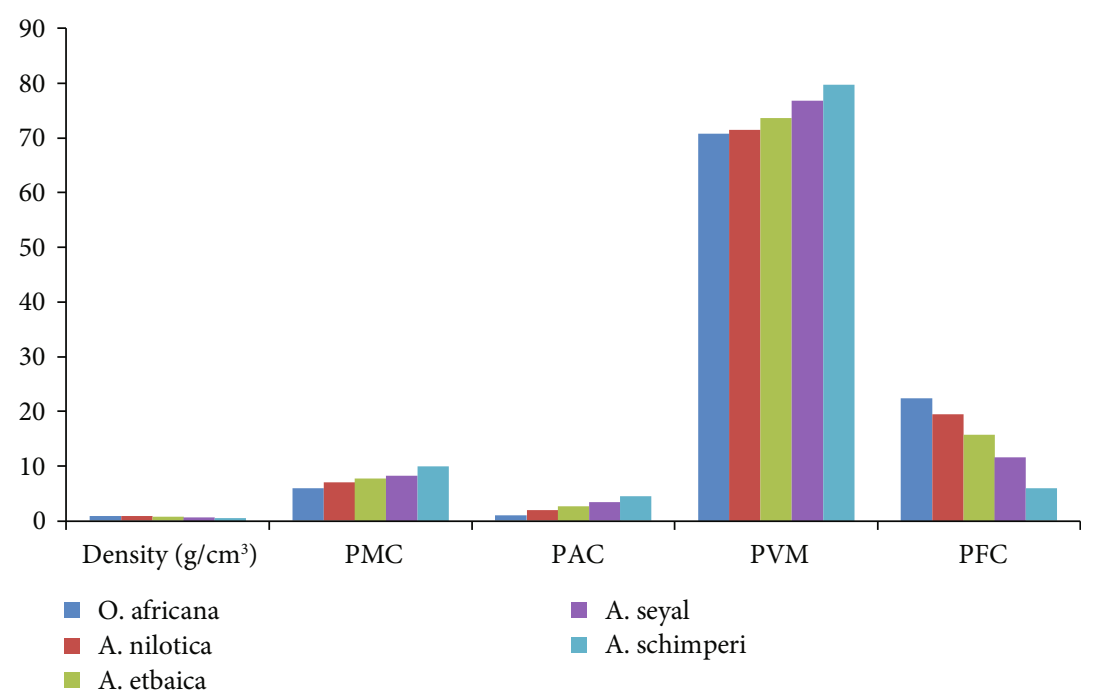

FiguRE 1: The energy properties of the preferred tree species.

$5 \%$ contingency is considered for households who may refuse to participate in the questionnaire.

Thus, using the above equation, the number of sample size for households was 134 .

2.2. Sample Collection Techniques. Based on preference of households, five tree species for firewood were identified. From the two kebeles that is Bale Anole and Gadulla, using the random sampling technique, Gadulla was selected. By going $300 \mathrm{~m}$ to the forest from Gadulla kebele, wood land inventory was taken in the customary wood land to assess the tree fuel species in the woody plant community. Then, by going up $120 \mathrm{~m}$ from the river burka, sample plots of 15 hectares were made through the wood lands using GPS. Thirty $20 \times 20 \mathrm{~m}$ subplots were placed in the customary wood lands randomly. In this 30 subplots, the total number of each species was counted: Olea africana 42, Acacia nilotica 67, Acacia etbaica 86, Acacia seyal 63, and Acokanthera schimperi 74. All preferable tree species in all subplots was registered. Using random sampling from the total population, each preferable tree species was selected, that is, the trunk of three separate trees for each species [15]. The tree trunk of each species collected had a diameter of 5 to $10 \mathrm{~cm}$ and a length of 20 to $30 \mathrm{~cm}$ of the mature tree (10 to 20 years old) from the lower tower approximately $3 \mathrm{~cm}$ from the branching to avoid localized swelling. A total of fifteen samples were collected for fuelwood. After leveling each sample, it was kept in the plastic bag until the first measurement was taken. All samples were weighed after two hours of cutting in the field using a measuring balance by removing their bark. Then, all samples were sun dried for four weeks at a temperature of $18^{\circ} \mathrm{C}$ to $27^{\circ} \mathrm{C}$.

2.3. Preferred Tree Species for Firewood. First, key informants were asked to name their preferred tree species for fuelwood. They listed seven species for fuelwood. From the seven species, the five selected species were Olea africana (ejersa),
Acokanthera schimperi (qaraaruu), Acacia nilotica (burquqqee), Acacia seyal (waaccuu), and Acacia etbaica (dodotti).

2.3.1. Results of the Questionnaire. According to the respondents, reliance upon firewood consumption in the district is alarmingly increasing.

From their indigenous accumulated knowledge, the communities have proposed orderly their preferred choice of fuelwood on the quality of burning as listed in Table 1. Thus, they preferred the five top species in the order of their preference: Acacia nilotica>Acacia etbaica > Olea africana $>$ Acacia seyal $>$ Acokanthera schimperi. These fuel characteristics preferred by the local users are similar to those of studies undertaken in Africa [19].

2.3.2. Preparation of Samples for Laboratory Analysis. For the determination of density, ash content, volatile matter, and moisture content, 15 samples were taken. Three trees were used from each species. A disk of $20 \mathrm{~cm}$ height was taken from the branch of each tree. Every disk was sawn into strips of $2.5 \mathrm{~cm}$ width. From the strips, 45 specimens were prepared for firewood. The strips are oven-dried prior to analysis. The samples were further comminuted with a wood machine except for density to obtain wood particles with a diameter of 1-2 mm. Smaller and larger particles were discarded.

\subsection{Procedures for Laboratory Analysis}

2.4.1. Determination of Fuelwood Density. The water displacement method allows for easy and reliable volume measurement for irregularly shaped samples. A container capable of holding the sample was filled with water and placed on a digital balance of precision $0.0001 \mathrm{~g}$. The balance was then rezeroed (the reading should be zero). The electronic balance should be rezeroed after every measurement. The oven-dried firewood and charcoal specimens were then carefully sunk in the water, such that it was completely underwater. 
TABlE 1: The tree species identified by key informants for firewood and the number of times each was mentioned among those selected species by the households.

\begin{tabular}{lcc}
\hline Botanical name & $\begin{array}{c}\text { Local name } \\
\text { (Afaan oromoo) }\end{array}$ & $\begin{array}{c}\text { Frequency of } \\
\text { preference }\end{array}$ \\
\hline (1) Acacia nilotica & Burquqqee & 93 \\
(2) Acacia etbaica & Dodotti & 88 \\
(3) Olea africana & Ejersa & 74 \\
(4) Acacia seyal & Waaccuu & 62 \\
(5) Acokanthera schimperi & Qaraaruu & 35 \\
\hline
\end{tabular}

2.4.2. Determination of the Percentage of Moisture Content (PMC). According to Akowuah et al. [3], for proximate biomass characterization, a $40 \mathrm{~g}$ to $158 \mathrm{~g}$ sample should be dried to constant weight in an oven at a temperature of $105^{\circ} \mathrm{C}$ for 14 hours. The loss in weight should be taken as moisture. The remaining weight should indicate the dry matter. The moisture content ought to be obtained by

$$
\mathrm{PMC}=\left(\frac{D}{E} \times 100\right),
$$

where $D$ is the change in weight after 14 hours and $E$ should be the weight of the dried sample.

2.4.3. Determination of the Percentage of Volatile Matter $(P V M)$. The percentage of volatile matter of the biomass materials was determined in accordance with ASTM International (2008) ASTM D3175-11 [15]. Approximately $40 \mathrm{~g}$ to $145 \mathrm{~g}$ of each of the biomass materials with particle size of 1-2 mm was placed in a porcelain crucible. Each sample was first oven-dried and then was kept in a furnace at a temperature of $550^{\circ} \mathrm{C}$ for $10 \mathrm{~min}$ and weighed after cooling in a desiccator. The percentage volatile matter was then calculated as follows:

$$
\mathrm{PVM}=\left(\frac{A-B}{A}\right) \times 100
$$

where $A$ is the weight of the oven-dried sample and $B$ is the weight of the sample after $10 \mathrm{~min}$ in the furnace at $550^{\circ} \mathrm{C}$.

2.4.4. Determination of the Percentage of Ash Content (PAC). The percentage of ash content of the biomass materials was determined in accordance with ASTM International (2008) ASTM D 1102-84 [15]. This was done by heating approximately $40 \mathrm{~g}$ to $145 \mathrm{~g}$ of oven-dried mass of each biomass material with particle size of $1-2 \mathrm{~mm}$, in an electric furnace (Carbolite CW $1300^{\circ} \mathrm{C}$, U.K.), at a temperature of $600^{\circ} \mathrm{C}$ for four hours. Thereafter, it was cooled and weighted to represent the ash content of the sample. The ash content was determined using the equation:

$$
\mathrm{PAC}=\frac{C}{A} \times 100
$$

where $C$ is the ash weight and $A$ is the weight of the sample.
2.4.5. Determination of the Percentage of Fixed Carbon (PFC). To determine the fixed carbon, get the sum of the volatile matter, moisture content, and ash content then subtract from 100. The balance is the fixed carbon content [3]:

$$
P F C=100-(P V M+P M C+P A C) .
$$

2.5. Data Analysis. SAS 9.4 was used for the statistical analysis with confidence level of $95 \%$ in the present work. Correlation analysis was also used to show the energy properties of wood samples with the percentage of fixed carbon.

\section{Results}

After each preferred tree species was dried up to four weeks at a temperature of $18^{\circ} \mathrm{C}$ to $27^{\circ} \mathrm{C}$, the moisture content was lost by each species: O. africana $14.61 \%$, A. nilotica $16.25 \%$, A. etbaica $18.35 \%$, A. seyal $24.34 \%$, and A. schimperi $27.44 \%$. Diameter of the preferred five tree species (each three samples) was prepared, and then, their corresponding densities and the percentage of moisture, ashes, volatile matter, and fixed carbon contents are tabulated in Table 2.

The experimental result proved that $O$. africana holds the highest fixed carbon content as seen in Table 2, whereas $A$. schimperi holds the least fixed carbon content in it. However, the local communities have mostly said that Acacia nilotica was primarily preferred. Their orderly preference from their responses was Acacia nilotica, Acacia etbaica, Olea africana, Acacia seyal, and A. schimperi. These discrepancy choices might be influenced by availability, flammability, and proximity to the wood species in the area.

3.1. Wood Density. In Table 2, column 3 showed the densities of five tree species used for the study. The densities of the species were ranged from $0.553 \mathrm{~g} / \mathrm{cm}^{3}$ (Acokanthera schimperi) to $0.914 \mathrm{~g} / \mathrm{cm}^{3}$ (Olea africana) as tabulated in Table 2. Olea africana proved to have the highest density woody species among others in the study samples. The result further suggests that Olea africana is more likely to have a higher energy per unit volume than the other species for firewood samples with higher correlation between its fixed carbon content as shown in Table 3. The result of the plot in Figure 1 has almost direct correlation relationships between density and fixed carbon value with a similar work on carbon property of wood published by [15].

3.2. The Moisture Content. According to Akowuah et al. [3], moisture content is a very important property which can greatly affect the burning characteristics of biomass. A just fallen tree contains $40 \%$ to $60 \%$ of hygroscopic moisture depending on the species of the tree as well as the seasons of the year [15]. Here, the samples dried up to four weeks only. In the fourth column of Table 2, the moisture content was ranged from 5.908 (Olea africana) to 9.927 (Acokanthera schimperi). O. africana has also the least moisture content and is inversely correlated with the fixed carbon content as graphed with another sample in Table 2 . Higher volatile matter is an indicator of the least fixed carbon content and vice versa. The plot in Figure 1 or the associated relation between 
TABLE 2: Experimental results and principal component analysis (PCA) on five tree species on their density and moisture, ash, volatile matter, and fixed carbon contents.

\begin{tabular}{|c|c|c|c|c|c|c|}
\hline Species name & Diameter $(\mathrm{cm})$ & Density $\left(\mathrm{g} / \mathrm{cm}^{3}\right)$ & $\begin{array}{c}\text { Moisture } \\
\text { contents (\%) }\end{array}$ & $\begin{array}{c}\text { Ash } \\
\text { contents (\%) }\end{array}$ & $\begin{array}{c}\text { Volatile matter } \\
\text { contents }(\%)\end{array}$ & $\begin{array}{l}\text { Fixed carbon } \\
\text { contents }(\%)\end{array}$ \\
\hline O. africana & 7.367 & $0.914^{\mathrm{a}}$ & $5.908^{c}$ & $0.994^{\mathrm{e}}$ & $70.710^{\mathrm{d}}$ & $22.388^{\mathrm{a}}$ \\
\hline A. nilotica & 6.400 & $0.857^{\mathrm{b}}$ & $7.030^{\mathrm{bc}}$ & $1.971^{\mathrm{d}}$ & $71.495^{\mathrm{dc}}$ & $19.503^{\mathrm{b}}$ \\
\hline A. etbaica & 6.300 & $0.779^{c}$ & $7.819^{\mathrm{bc}}$ & $2.741^{\mathrm{c}}$ & $73.644^{c}$ & $15.796^{\mathrm{c}}$ \\
\hline A. seyal & 6.667 & $0.665^{\mathrm{d}}$ & $8.279^{\mathrm{ba}}$ & $3.353^{\mathrm{b}}$ & $76.790^{\mathrm{b}}$ & $11.578^{\mathrm{d}}$ \\
\hline A. schimperi & 5.800 & $0.553^{\mathrm{e}}$ & $9.927^{\mathrm{a}}$ & $4.445^{\mathrm{a}}$ & $79.673^{\mathrm{a}}$ & $5.954^{\mathrm{e}}$ \\
\hline
\end{tabular}

Values followed by the same superscript letters in each column are not significantly different at $\alpha=0.05$ according to Duncan's multiple range tests.

TABLE 3: Correlations of average energy properties of wood samples with its percentage of fixed carbon.

\begin{tabular}{ccccc}
\hline & Density & PMC & PAC & PVM \\
\hline PFC & 0.982 & -0.873 & -0.941 & -0.971 \\
\hline
\end{tabular}

them in Table 3 have a similar work output on the biomass properties published by dos Santos Viana et al. [20].

3.2.1. The Ash Content. In the fifth column of Table 2, the ash content ranges from 0.994 (Olea africana) to 4.445 (Acokanthera schimperi).

According to Álvarez-Álvarez et al. [21], the tree species with the highest fixed carbon hold up the least ash content. Similar observations are found in this research. That means as the percentage of ash content increases, the percentage of fixed carbon decreases as observed in Table 3. The high ash content of Acokanthera schimperi indicates that it has high mineral content [15]. According to Ijagbemi et al. [22], ash has significant influence on the heat transfer to the surface of the fuel as well as the diffusion oxygen to the fuel surface during char combustion.

3.2.2. Volatile Matter. Volatile matter refers to the part of a biomass material that is released as volatile gases when it is heated up to $400^{\circ} \mathrm{C}$ to $500^{\circ} \mathrm{C}$. Volatile matter represents the components of carbon, hydrogen, and oxygen present in the biomass that when heated turn to vapour, usually a mixture of short- and long-chain hydrocarbons [23]. From Table 3, volatile matter is inversely proportional to the percentage of fixed carbon. That is, as volatile matter increases, the percentage of fixed carbon decreases and vice versa. $O$. africana has still the least PVM among other woody species in the sample. Volatile content has been shown to influence the thermal behavior of solid fuels [3]. However, this in turn is influenced by the structure and bonding within the fuel. As Akowuah et al. [3] reported, low-grade biomass, such as dung, tends to have a low volatile content resulting in smouldering combustion. They further stated that it results in an incomplete combustion which leads to a significant amount of smoke and toxic gases being released. No particular trend is observed for volatile matter content and the fixed carbon content with tree age [24].

In general, the plots in Figure 1 and their associated relations of PMC, PAC, and PVM with PFC determined experi- mentally as in Table 2 have similar work outputs on the biomass properties published by dos Santos Viana et al. [20].

3.2.3. Fixed Carbon. The fixed carbon of a fuel indicates the percentage of carbon available for char combustion. It is not equal to the total amount of carbon in the fuel since a significant amount is released as hydrocarbons in the volatile. The percentage of fixed carbon in Table 2 column 7 ranges from $5.955 \%$ (A. schimperi) to $22.388 \%$ (Olea africana) in the firewood samples. The general trend shows that the percentage of fixed carbon (PFC) increases as the density increases evidently from laboratory results shown in Table 2. Further, PFC decreases as the percentage of ash content, moisture content, and volatile matter increases observed from laboratory results shown in Table 2 .

Further, Table 3 describes the correlation analysis of wood density, PMC, PVM, and PAC with PFC. The density $(r=0.982)$ is positively correlated with PFC, PMC $(r=-0.873)$ is correlated negatively with PFC, PAC $(r=-0.941)$ is correlated negatively with PFC, and PVM $(r=-0.971)$ is correlated negatively with PFC. This indicates that the increment of one of the energy properties increases or decreases the other properties. For example, increase of density decreases PMC, PAC, and PVM, whereas increases PFC. Similarly, the increase of PMC increases PAC and PVM but decreases density and PFC. The significance analysis of PMC, PAC, and PVM in determining the fixed carbon content in this table would be of great importance in determining the fuel properties of not only fuelwood but also biomass, wood pellets, and other fuel sources [25].

\section{Discussion}

The density of the biomass material plays an important role in the determination of its fuel value. Denser wood contains more heat per unit volume in that they tend to burn for longer periods of time. Significant differences in densities were found among wood samples used $(P<0.05)$. These variations might be due to the differences in the age of tree species and/or environmental conditions [22]. The main physical properties affecting the performance of fuelwood are moisture content, chemical, elemental composition, and wood density [15]. Increased moisture in the wood results in a decrease in the obtained amount of heat, as more energy is used to evaporate to water, which lowers the combustion efficiency [26]. For complete combustion of the wood samples of 
the tree species, there should be a need to remove the water in them by evaporation. Like densities, the percentages of moisture content in various fuelwood samples used were significantly different $(P<0.05)$ as shown in Table 2. These variations might be due to the differences in the age of tree species and/or environmental conditions as well as variations in species.

The percentage of ash content in various fuelwood samples used for these analyses was significantly different $(P<0.05)$ as shown in Table 2. The ash consists of mineral water that is found in the wood itself, with an admixture of some impurities which were acquired during transportation. The mineral matter is distributed throughout the tree rather irregularly. The ash consists of mainly potassium carbonate with varying degrees of calcium, magnesium, and sodium carbonate as well as minute quantities of iron oxide, alumina, and silica. Pure ash is white in color [13]. A high ash content of a plant part makes it less desirable as fuel, because a considerable part of the volume cannot be converted into energy $[23,27]$. In general, tropical species are said to have comparatively high ash content and moisture content [14]. Ash deposit on heat transfer surfaces in boilers and internal surfaces in gasifiers accelerates corrosion of hot heat exchanging tubes and also reduces their efficiency [15]. The ash content is much higher in lower aged (2-6 years old) trees compared to matured trees (20 years old) [24].

The high volatile matter content of a biomass material indicates that during combustion, most of it will volatilize and burn as gas in the cookstove [15]. Biomass generally has a volatile content around $70-86 \%$ of the weight of the dry biomass which makes biomass a more reactive fuel giving a much faster combustion rate during the devolatilization phase than other fuels such as coal [15]. Table 2 shows the variations of volatile matter among different fuelwood samples used $(P<0.05)$.

There is a significant difference in proportion of fixed carbon among fuelwood samples used $(P<0.05)$. The variation in fixed carbon content was shown in Table 2. The varying fixed carbon content was observed as the result of low ash content which is associated with high lignin content in the wood used [22].

\section{Conclusion}

This study assessed the fuel properties of five tree species. It can be concluded from the results that all species studied had density ranging from 0.553 to $0.914 \mathrm{~g} / \mathrm{cm}^{3}$, moisture content 5.908 to $9.927 \%$, ash content 0.994 to $4.445 \%$, and volatile matter and fixed carbon 70.710 to $79.673 \%$ and 5.955 to $22.388 \%$, respectively. O. africana has the highest fixed carbon, whereas Acokanthera schimperi has the least fixed carbon. Moisture content, ash content, and volatile matters are the key parameters to be determined to predict the carbon content of the species. The preference of wood fuels is not dependent on the single energy properties of the species rather a holistic characterization of PFC, PAC, PMC, PMV, and density. Preference wood fuels by households are not only on the basis of energy properties of fuelwood but also by including the availability, flammability, and proximity to the study area. The preference choice of tree species for fuelwood should rely on scientific assessment to satisfy the local communities at large.

It could further be concluded from the study; the species have relatively high moisture content and volatile matter content but low fixed carbon content. It is advisable to conduct further study on the present status and coppice management of the preferred tree species.

\section{Data Availability}

The data used to support the findings of this study are available from the corresponding author upon request.

\section{Conflicts of Interest}

The authors declare that they have no conflicts of interest.

\section{References}

[1] P. A. Owusu and S. Asumadu-Sarkodie, "A review of renewable energy sources, sustainability issues and climate change mitigation," Cogent Engineering, vol. 3, no. 1, article 1167990, 2016.

[2] O. M. Bamiro and J. O. Ogunjobi, "Determinants of household energy consumption in Nigeria: evidence from Ogun State," Research Journal of Social Science and Management, vol. 4, no. 12, pp. 35-41, 2015.

[3] J. O. Akowuah, F. Kemausuor, and S. J. Mitchual, "Physicochemical characteristics and market potential of sawdust charcoal briquette," International Journal of Energy and Environmental Engineering, vol. 3, no. 1, pp. 20-26, 2012.

[4] M. A. H. Mondal, E. Bryan, C. Ringler, D. Mekonnen, and M. Rosegrant, "Ethiopian energy status and demand scenarios: prospects to improve energy efficiency and mitigate GHG emissions," Energy, vol. 149, pp. 161-172, 2018.

[5] P. Rafaj, G. Kiesewetter, T. Gül et al., "Outlook for clean air in the context of sustainable development goals," Global Environmental Change, vol. 53, pp. 1-11, 2018.

[6] G. T. Tucho and S. Nonhebel, "Alternative energy supply system to a rural village in Ethiopia," Energy, Sustainability and Society, vol. 7, no. 33, pp. 1-14, 2017.

[7] M. Iiyama, H. Neufeldt, P. Dobie, M. Njenga, G. Ndegwa, and R. Jamnadass, "The potential of agroforestry in the provision of sustainable woodfuel in sub- Saharan Africa," Current Opinion in Environmental Sustainability, vol. 6, pp. 138-147, 2014.

[8] J. Chamberlin, T. S. Jayne, and D. Headey, "Scarcity amidst abundance? Reassessing the potential for cropland expansion in Africa," Food Policy, vol. 48, pp. 51-65, 2014.

[9] C. R. Lohri, H. M. Rajabu, D. J. Sweeney, and C. Zurbrügg, "Char fuel production in developing countries - A review of urban biowaste carbonization," Renewable and Sustainable Energy Reviews, vol. 59, pp. 1514-1530, 2016.

[10] J. Szulecka and L. Secco, "Local institutions, social capital and their role in forest plantation governance: lessons from two case studies of smallholder plantations in Paraguay," International Forestry Review, vol. 16, no. 2, pp. 180-190, 2014.

[11] S. Bouzarovski and S. Petrova, "A global perspective on domestic energy deprivation: Overcoming the energy poverty-fuel poverty binary," Energy Research \& Social Science, vol. 10, pp. 31-40, 2015. 
[12] K. Sander, B. Hyseni, and S. W. Haider, Wood-based biomass energy development for sub-Saharan Africa: issues and approaches, The World Bank, Washington, DC, USA, 2011.

[13] F. Ruiz-Aquino, M. M. González-Peña, J. I. Valdez-Hernández, U. S. Revilla, and A. Romero-Manzanares, "Chemical characterization and fuel properties of wood and bark of two oaks from Oaxaca, Mexico," Industrial Crops and Products, vol. 65, pp. 90-95, 2015.

[14] A. Pirraglia, R. Gonzales, D. Saloni, J. Wright, and J. Denig, "Fuel properties and suitability of Eucalyptus benthamii and Eucalyptus macarthurii for torrefied wood and pellets," Bio Resources, vol. 7, no. 1, pp. 217-235, 2012.

[15] S. J. Mitchual, K. Frimpong-Mensah, and N. A. Darkwa, "Evaluation of fuel properties of six tropical hardwood timber species for briquettes," Journal of Sustainable Bioenergy Systems, vol. 4, no. 1, pp. 1-9, 2014.

[16] D. D. Guta, "Effect of fuelwood scarcity and socio-economic factors on household bio-based energy use and energy substitution in rural Ethiopia," Energy Policy, vol. 75, pp. 217-227, 2014.

[17] Z. M. Gebretsadik, "Productivity of Eucalyptus camaldulensis (Dehnh.) in Goro Woreda of Bale zone, Ethiopia," Research Journal of Agriculture and Environmental Management, vol. 2, no. 9, pp. 252-260, 2013.

[18] G. D. Israel, "Determining sample size," 1992, Fact Sheet PEOD-6.

[19] P. Techato and K. Techato, "Patterns of firewood use among ethnic minority communities and local forest management: a case study in Pu Hu nature reserve, Vietnam," Applied Ecology and Environmental Research, vol. 16, no. 4, pp. 4229-4249, 2018.

[20] H. F. dos Santos Viana, A. M. Rodrigues, R. Godina, J. C. de Oliveira Matias, and L. J. R. Nunes, "Evaluation of the physical, chemical and thermal properties of Portuguese maritime pine biomass," Sustainability, vol. 10, no. 8, article 2877, 2018.

[21] P. Álvarez-Álvarez, C. Pizarro, M. Barrio-Anta et al., "Evaluation of tree species for biomass energy production in Northwest Spain," Forests, vol. 9, no. 4, p. 160, 2018.

[22] C. O. Ijagbemi, S. O. Adepo, and K. S. Ademol, "Evaluation of combustion characteristic of charcoal from different tropical wood species," IOSR Journal of Engineering, vol. 4, no. 4, pp. 50-57, 2014.

[23] S. Van Loo and J. Koppejan, The Handbook of Biomass Combustion and Co-Firing, Earthscan, 2012.

[24] R. Kumar, K. K. Pandey, N. Chandrashekar, and S. Mohan, "Study of age and height wise variability on calorific value and other fuel properties of Eucalyptus hybrid, Acacia auriculaeformis and Casuarina equisetifolia," Biomass and Bioenergy, vol. 35, no. 3, pp. 1339-1344, 2011.

[25] I. E. Onukak, I. A. Mohammed-Dabo, A. O. Ameh, S. I. R. Okoduwa, and O. O. Fasanya, "Production and characterization of biomass briquettes from tannery solid waste," Recycling, vol. 2, no. 4, p. 17, 2017.

[26] M. F. Chagunda, C. Kamunda, J. Mlatho, C. Mikeka, and L. Palamuleni, "Performance assessment of an improved cook stove (Esperanza) in a typical domestic setting: implications for energy saving," Energy, Sustainability and Society, vol. 7, no. 1, pp. 1-9, 2017.

[27] L. J. R. Nunes, J. C. D. O. Matias, and J. P. D. S. Catalao, Torrefaction of Biomass for Energy Applications: From Fundamentals to Industrial Scale, Academic Press, 2017. 